СТАТЬИ

УДК $630 * 161(571.56)$

ИССЛЕДОВАНИЕ ЛЕСОВОССТАНОВИТЕЛЬНЫХ ПРОЦЕССОВ В СОСНОВЫХ ЛЕСАХ ПОСЛЕ ПОЖАРОВ РАЗНЫХ ЛЕТ И РАЗРАБОТКА ПРОЕКТА ИСКУССТВЕННОГО ВОЗОБНОВЛЕНИЯ (НА ПРИМЕРЕ МЕГИНО-КАНГАЛАССКОГО УЛУСА РЕСПУБЛИКИ САХА (ЯКУТИЯ))

\author{
${ }^{1}$ Борисов С.В., ${ }^{1}$ Сергучева А.И., ${ }^{2}$ Иванова О.Н. \\ ${ }^{\prime}$ МБОУ «Майинский лицей имени И.Г. Тимофеева», \\ Мегино-Кангаласский улус Республика Саха, Якутия, е-таil: gyтптауа@таil.ru; \\ ${ }^{2}$ ФГБОУ ВО «Якутская государственная сельскохозяйственная академия», \\ Якутск, e-mail: ysaa.ykt@gmail.com
}

\begin{abstract}
Данная статья посвящена исследованию лесовосстановительных процессов в сосновых лесах после пожаров разных лет и разработке проекта искусственного возобновления в Мегино-Кангаласском улусе. Здесь рассматриваются такие вопросы, как сравнение интенсивности лесовосстановительных процессов в сосновых лесах после низовых пожаров разных лет и исследование видового состава растений соснового леса. В статье использовались следующие методы исследования: изучение и анализ отечественной литературы по проблеме исследования; проведение маршрутных исследований; исследование типа почвы и видов растений; ведение учета подроста сосны на пробных площадках; проведение сбора семян сосны, выращивание саженцев сосны по экспериментальным методикам. Проведенное исследование позволило нам сделать следующие выводы: 1) сосновые леса в течение одного года и трех лет после пожаров не были восстановлены в связи с недостаточной увлажненностью почвы; 2) лесовосстановительные процессы после пожаров 10-летней давности идут медленно, подрост достигает высоты в среднем 1 м; 3) 70\% территории после пожара 10-летней давности не было восстановлено в связи с вторичным пожаром 3-летней давности; 4) после низового пожара 30-летней давности сосновый лес интенсивно восстанавливается и подрост достигает высоты в среднем 8-9 м; 5) по сравнению с контрольными участками на территориях после пожаров 10-летней давности лесовосстановление идет интенсивнее в 1,5 раза; 6) за 1 год подрост сосны в возрасте до 10 лет растет медленнее (10 см), а рост подроста в возрасте до 30-40 лет идет более интенсивно (30 и 33 см соответственно); 7) выращивание саженцев сосны осуществляется по экспериментальным методикам.
\end{abstract}

Ключевые слова: подрост, низовые пожары, разновозрастные гари

\title{
STUDY OF REFORESTATION PROCESSES IN PINE FOREST AFTER FIRES OF DIFFERENT YEARS AND THE DEVELOPMENT OF THE PROJECT OF ARTIFICIAL REGENERATION (ON THE EXAMPLE OF MEGINO-KANGALASSKIY DISTRICT REPUBLIC OF SAKHA (YAKUTIA)
}

${ }^{1}$ Borisov S.V., ${ }^{1}$ Sergucheva A.I., ${ }^{2}$ Ivanova O.N.

${ }^{\prime}$ Mayinsky Lyceum named after I.G. Timofeev, Megino-Kangalassky ulus Republic of Sakha, Yakutia,e-mail:gymnmaya@mail.ru;

${ }^{2}$ Yakut State Agricultural Academy, Yakutsk, e-mail: ysaa.ykt@gmail.com

\begin{abstract}
This article is devoted to the study of reforestation processes in pine forests after fires of different years and the development of a project of artificial regeneration in Megino-Kangalassky ulus. The article discusses such issues as comparing the intensity of reforestation processes in pine forest after fires of different years and studying the species composition of plants. The following research methods were used: study and analysis of Russian literature on the research problem; conducting route research; study of soil type and plant species; keeping records of pine undergrowth at sample plots; collecting pine seeds, growing seedlings according to experimental methods. Our study allowed us to draw the following conclusions: 1) pine forests after fires of 1 and 3 years were not restored due to insufficient soil moisture; 2) reforestation processes after fires of 10 years ago are slow, undergrowth reaches an average height of $1 \mathrm{~m}$; 3) $70 \%$ of territory covered by fire of 10 years ago has not been restored due to secondary fire of 3 years ago; 4) after ground fire of 30 years ago, pine forest is being intensively restored and undergrowth reaches an average height of $8-9$ meters; 5) compared to the control plots in territories covered by fires 10 years ago, reforestation is 1.5 times more intensive; 6) during a year undergrowth under age of 10 grows slower $(10 \mathrm{~cm})$, and growth of undergrowth under age of 30-40 years is more intensive (30 and $33 \mathrm{~cm})$; 7) seedlings are grown by experimental methods.
\end{abstract}

Keywords: undergrowth, ground fires, burnt areas of different ages

В республике Саха (Якутия) из года в год возникают лесные пожары различной интенсивности и занимают большие территории. Так, в последние годы наблюдается тенденция увеличения площади и количества пожаров именно в Централь- ной Якутии [1, с. 50]. Например, за период с 1955 по 2010 г. в Якутии зарегистрировано около 30 тыс. пожаров [2, с. 20], в том числе за последние 10 лет - более 8500 пожаров на общей площади почти 2,5 млн га [3, с. 8$]$. В соответствии с лесопожарным райони- 
рованием лесного фонда республики, Мегино-Кангаласский улус (район) относится к Центрально-Якутской равнинной области, где средний класс пожарной опасности составляет 2,95 [4, с. 122] и где, согласно сведениям ГКУ РС (Я) «Мегино-Кангаласское лесничество», в последнее десятилетие пожаром был уничтожен лесной массив площадью 18130 га [5, с. 37]. В естественных условиях в различных типах лесов процесс лесовозобновления идёт с различной интенсивностью. Исходя из этого исследование лесовосстановительных процессов в сосновых лесах после пожаров имеет актуальное значение.

Цель: исследование лесовосстановительных процессов в сосновых лесах после пожаров разных лет и разработка проекта искусственного возобновления на месте пожара 10-летней давности.

\section{Материалы и методы исследования}

Изучение и анализ отечественной литературы по проблеме исследования; составление плана исследования и проведение маршрутных исследований на территории Мегино-Кангаласского улуса в окрестностях с. Хаптагай, а также на территории Нерюктяйского наслега в детском экологическом парке «Моро», где основными приемами явились: проведение учета подроста по породам и категориям высот по рекомендуемым учеными группам высот: 1 группа $0-10 ; 2$ - 11-50; 3 - 51-150; 4 - свыше 150 см на этих площадках; определение возраста подроста сосны обыкновенной на исследуемых участках; вычисление прироста подроста сосны обыкновенной за 1 год; проведение сбора семян сосны обыкновенной и определение всхожести их семян, а также определение типа почвы по описанию; ис- следование видового состава растений соснового леса и проведение сравнительного анализа естественного лесовосстановления соснового леса после пожаров разных лет и искусственного лесовосстановления (сентябрь - октябрь 2020 г.).

Также планируется экспериментальная работа по выращиванию 700 саженцев сосны обыкновенной методом гидропоники в четырех разных растворах в лабораторных условиях и в мини-питомнике и их выборка по результатам пяти экспериментов (февраль - май 2020 г.). А также разработка технологии по выращиванию и посадке саженцев сосны обыкновенной в условиях многолетней мерзлоты на основе экспериментальных работ (ноябрь - декабрь 2020 г.).

Для того чтобы выявить состояние естественного лесовозобновления на разновозрастных гарях, авторы провели маршрутные исследования на территории Мегино-Кангаласского улуса: заложены и исследованы 3 пробных участка размерами $10 * 10$ м в детском экологическом парке «Моро» на территории Нерюктяйского наслега и 4 контрольных участка в окрестности села Хаптагай.

\section{Результаты исследования и их обсуждение}

Как было сказано выше, ежегодно лесные пожары различной интенсивности возникают в нашей республике. За период с 1955 по 2010 г., по мнению исследователей, наиболее пожароопасными были 1973 , 1984-1987, 1990-1993, 1996, 2001-2003 гг., когда регистрировалось свыше 800 пожаров. В целом ученые выделяют 4-6-летние, 10-14-летние циклы высокой горимости лесов Якутии, что в общем более или менее совпадает с цикличностью природных процессов [2, с. 20].

Таблица 1

Площади лесных пожаров в Мегино-Кангаласском районе с 1973 по 2018 г.

\begin{tabular}{|c|c|c|c|c|c|c|c|c|c|c|}
\hline Год & 2011 & 2012 & 2013 & 2014 & 2015 & 2016 & 2017 & 2018 & & \\
\hline га & 15842 & 356,6 & 397 & 7 & - & 281 & 232,1 & 217,2 & & \\
\hline Год & 2001 & 2002 & 2003 & 2004 & 2005 & 2006 & 2007 & 2008 & 2009 & 2010 \\
\hline га & 2366 & 12298 & 1028,1 & 90,8 & 14,3 & 33,3 & 16,4 & 3 & 201 & 596,1 \\
\hline Год & 1991 & 1992 & 1993 & 1994 & 1995 & 1996 & 1997 & 1998 & 1999 & 2000 \\
\hline га & 197,4 & 1219 & 1111,9 & 1030,8 & 3 & 9342 & 1031 & 751,8 & 41,3 & 236,6 \\
\hline Год & 1981 & 1982 & 1983 & 1984 & 1985 & 1986 & 1987 & 1988 & 1989 & 1990 \\
\hline га & 47 & 6 & 47 & 177,95 & 52,3 & 7181,3 & 7324,1 & 84 & 12,3 & 212,7 \\
\hline Год & 1971 & 1972 & 1973 & 1974 & 1975 & 1976 & 1977 & 1978 & 1979 & 1980 \\
\hline га & нет данных & нет данных & 715 & 6,7 & 23,6 & 4,4 & 31,75 & 32,2 & 5 & 13,56 \\
\hline
\end{tabular}

П р и м еч а н и е. Выделение: красный - свыше 10 тыс. га; желтый - свыше 5 тыс. га; фиолетовый - свыше 2 тыс. га; синий - свыше 1 тыс. га. 
По мнению некоторых исследователей, лесные пожары способствуют успешному лесовозобновлению [6, с. 25]. Как отмечают П.А. Цветков, Л.В. Буряк, лесные пожары создают условия для появления нового поколения леса: пожары стимулируют быстрое и полное высвобождение из шишек оставшихся семян, а также формируют благоприятные условия для появления роста всходов.

Другие исследователи отмечают отрицательное влияние пожаров на успешность лесовосстановления. Ученые считают, что пожары сильной интенсивности разрушают лесную растительность, вследствие чего одно растительное сообщество может смениться другими, более устойчивыми к пожару. При беглых и низовых пожарах средней интенсивности повреждается только верхний слой подстилки, особенно лиственных пород. Здесь к неблагоприятным факторам среды исследователи также относят: экстремальную температуру, резкое снижение послепожарного гумуса, отсутствие обсеменителей и уничтожение лесной среды в целом [7, с. 53].

Третьи исследователи дополняют вышеизложенное следующими заключениями: они считают, что процесс послепожарного лесовосстановления может проходить по двум основным путям: 1) успешное лесовосстановление при условии сохранения устойчивости многолетнемерзлых пород; 2) неудовлетворительное лесовозобновление при нарушении устойчивости многолетнемерзлых пород. Во втором случае могут начаться термокарстовые процессы, образоваться термокарстовые просадки, провалы и, как следствие, термокарстовые озера, то есть лесовозобновление может замедлиться на десятки лет или может быть прерван лесовосстановительный процесс [8, с. 49].

Некоторые исследователи подчеркивают, что естественное лесовосстановление зависит от интенсивности и срока давности пожара, возраста и условий произрастания древесины, степени задернения почвы, наличия источников обсеменения [9, с. 56].

Итак, разделяя точку зрения Н.В. Гордея и Е.А. Тегленкова, мы, как было отмечено выше, провели маршрутное исследование в экологическом парке, расположенном на территории Нерюктяйского наслега на северной стороне от озера Моро. Здесь нами были заложены 3 участка размерами $10 * 10$ м, был исследован видовой состав растений соснового бора, опреде- лен тип почвы и проведены учеты подроста на этих площадках.

Участок № 1 расположен на северной стороне заповедной зоны. На участке были обнаружены 5 экземпляров подроста сосны обыкновенной высотой от 0 до $10 \mathrm{~cm}$, 26 штук подроста от 11 до 50 см, 10 единиц подроста от 51 см до 1,5 м, 2 подроста свыше $1,5 \mathrm{M}$.

На участке № 2 были обнаружены 1 экземпляр подроста сосны обыкновенной высотой от 0 до $10 \mathrm{~cm}, 25$ экземпляров от 11 до $50 \mathrm{~cm}, 7$ экземпляров от $51 \mathrm{~cm}$ до 1,5 м, свыше 1,50 м - 3 экземпляра.

На участке № 3 был обнаружен подрост сосны обыкновенной высотой от 0 до $10 \mathrm{cm-}$ 5 экземпляров, от 11 см до 50 см - 19 образцов, от 51 см до 1,5 м - 9 единиц, свыше 1,5 м - 3 штуки.

Более наглядно данная информация представлена в табл. 2.

Таблица 2

Сравнение количества подростов сосны на площадках эко-парка «Моро»

\begin{tabular}{|c|c|c|c|c|}
\hline № участка & $0-10 \mathrm{~cm}$ & $11-50 \mathrm{~cm}$ & $51-150 \mathrm{~cm}$ & $\begin{array}{c}\text { свыше } \\
150 \mathrm{~cm}\end{array}$ \\
\hline 1 участок & 5 & 26 & 10 & 2 \\
\hline 2 участок & 1 & 25 & 7 & 3 \\
\hline 3 участок & 5 & 19 & 9 & 3 \\
\hline
\end{tabular}

Таким образом, естественное восстановление соснового бора идет интенсивно там, где преобладает подрост сосны обыкновенной высотой до $50 \mathrm{~cm}$.

Также было проведено второе маршрутное исследование лесовосстановительных процессов в сосновых лесах в окрестности села Хаптагай, где были заложены 4 участка.

Участок № 1. Сосновый лес, где был пожар в 2018 г., расположен на расстоянии 9 км от села Хаптагай. Площадь пожара равна 4 га. Пожар был низовой. На I-м ярусе растет сосна обыкновенная, высотой 16 м, диаметром 15 см. Высота подпалины деревьев в среднем 2,0-2,40 м. Полностью уничтожены пожаром кустарники, мхи и лишайники. После пожара остались «островки» брусники обыкновенной. Естественное восстановление леса не наблюдается.

Участок № 2. Сосновый лес, где был пожар 3 года назад (2017 г.), расположен на расстоянии 8 км от села Хаптагай. Площадь пожара равна 300 га. Пожар также был низовой. На I-м ярусе растет сосна обыкновенная, высотой 13 м, диаметром 15 см. Частично уничтожены пожаром кустарни- 
ки, травы и сосны. Обнаружены отдельные экземпляры осоки, брусники обыкновенной. Естественное восстановление леса не наблюдается.

Участок № 3. Сосновый лес, где был пожар 10 лет (2009 г.) назад, расположен на расстоянии 1,5 км от села Хаптагай. Площадь низового пожара равна 1 га. На участке одиночно растут береза плосколистная, осина, лиственница Каяндера, ива узколистная, свидина белая. Травянисто-кустарничковый ярус представлен «островками» толокнянки боровой, растут осока, иван-чай, вейник Лансдорфа. Был обнаружен подрост сосны высотой от 0 до $10 \mathrm{~cm}-2$ экземпляра, от 11 до $50 \mathrm{~cm}-58$ образцов, от $51 \mathrm{~cm}$ до 1,5 м - 24 единиц, свыше 1,5 - 7 штук. В среднем прирост подроста сосны за 1 год равен $10 \mathrm{~cm}$.

Участок № 4. Сосновый лес, где был пожар 30 лет назад (1989 г.), расположен на расстоянии 3 км от села Хаптагай. Площадь низового пожара равна 1-2 тыс. га. Был обнаружен подрост сосны высотой в среднем 8-9 м, диаметром 8-9 см. В среднем прирост подроста сосны обыкновенной за 1 год составил $30 \mathrm{~cm}$. Возраст подростов сосны равен 23-27 лет. На месте пожара не обнаружено кустарников, а травяно-кустарничковый ярус представлен осокой, толокнянкой боровой. Был обнаружен подрост сосны высотой от 0 до $10 \mathrm{~cm}-3$ экземпляра, от $11 \mathrm{~cm}$ до $50 \mathrm{~cm}-23$, от $51 \mathrm{~cm}$ до 1,5 м - 5, свыше 1,5 м - 12 .

Более подробно с данной информацией можно ознакомиться в табл. 3 и 4, а также на графике (рисунок).

Таблица 3

Сравнение количества подроста сосны в окрестности села Хаптагай

\begin{tabular}{|c|c|c|c|c|}
\hline № участка & $0-10 \mathrm{~cm}$ & $11-50 \mathrm{~cm}$ & $51-150 \mathrm{~cm}$ & $\begin{array}{c}\text { свыше } \\
150 \mathrm{~cm}\end{array}$ \\
\hline 1 участок & - & - & - & - \\
\hline 2 участок & - & - & - & - \\
\hline 3 участок & 2 & 58 & 24 & 7 \\
\hline 4 участок & 3 & 23 & 5 & 12 \\
\hline
\end{tabular}

Видовой состав растений участков в окрестности с. Хаптагай

Таблица 4

\begin{tabular}{|c|c|c|c|c|}
\hline № участка & $\begin{array}{c}\text { I ярус } \\
\text { (высота, диаметр) }\end{array}$ & II ярус & III ярус & IV ярус \\
\hline 1 & $\begin{array}{c}\text { сосна обыкновенная } \\
\mathrm{H}=16 \text { м, D = 15 cм } \\
\text { высота подпалины 2-2,4 м }\end{array}$ & нет & $\begin{array}{c}\text { островки брусники } \\
\text { обыкновенной } \\
\text { п.П. }=80-90 \% \\
\end{array}$ & нет \\
\hline 2 & $\begin{array}{c}\text { сосна обыкновенная } \\
\mathrm{H}=13 \mathrm{~m}, \mathrm{D}=15 \mathrm{~cm}\end{array}$ & нет & $\begin{array}{c}\text { осока, } \\
\text { брусника обыкновенная }\end{array}$ & частично \\
\hline 3 & $\begin{array}{c}\text { лиственница Каяндера, } \\
\text { береза плосколистная, осина }\end{array}$ & $\begin{array}{l}\text { ива узколистная, } \\
\text { свидина белая }\end{array}$ & $\begin{array}{c}\text { осока, толокнянка боровая, } \\
\text { иван-чай, вейник Лансдорфа }\end{array}$ & нет \\
\hline 4 & $\begin{array}{c}\text { сосна обыкновенная } \\
\mathrm{D}=15 \mathrm{~cm}\end{array}$ & нет & осока, толокнянка боровая & нет \\
\hline
\end{tabular}

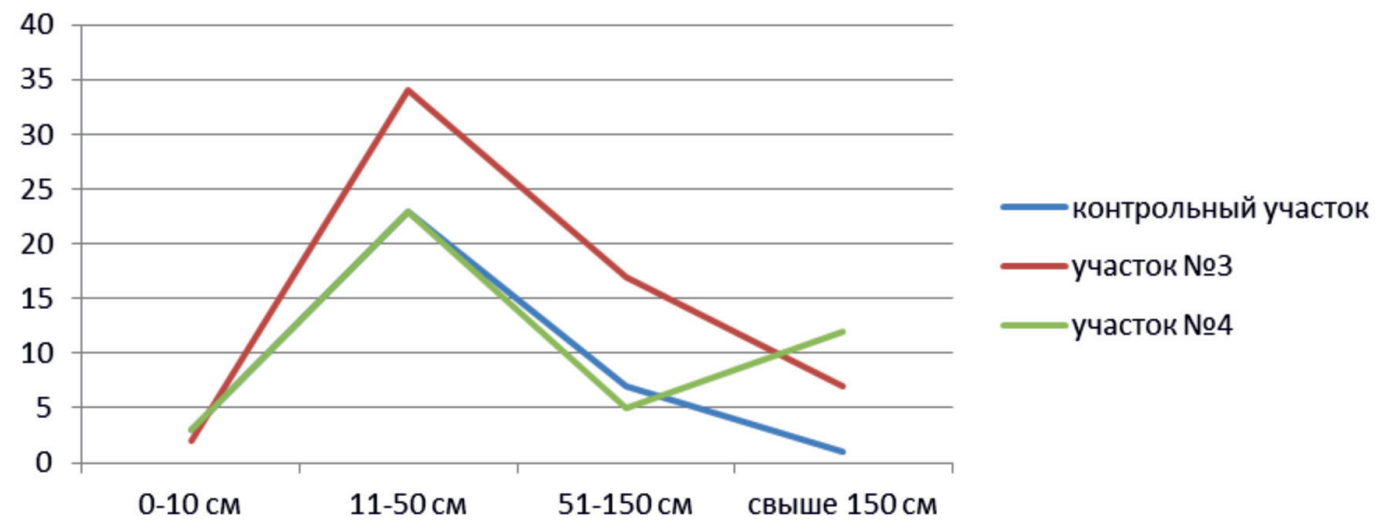

Сравнение количества подростов сосны на контрольных участках и горельниках 10-, 32-летней давности 
Также мы посетили сосновый бор, где в 1979 г. силами учащихся Хаптагайской средней школы были посеяны семена сосны обыкновенной на пустыре площадью 1 га. Через 40 лет на этом месте вырос огромный лес.

Итак, какое решение по лесовосстановлению после пожаров разных лет предлагают исследователи?

Ученые считают, что основным способом лесовосстановления нарушенных площадей лесов является естественное лесовозобновление и меры содействия этому процессу. На нарушенных территориях, не обеспеченных достаточным количеством подроста предварительного возобновления и обсеменением, необходимо проведение специальных лесокультурных мероприятий [2, с. 39].

Авторы, в свою очередь, на основе проведенного исследования разработали проект искусственного возобновления соснового бора на территории, охваченной пожаром 10-летней давности. В конце января 2020 г. мы провели сбор семян сосны обыкновенной в сосновом бору в окрестностях с. Хаптагай. Шишки сосны просушили при температуре $25-30^{\circ} \mathrm{C}$. 13 февраля 2020 г. семена намочили и провели определение всхожести семян в процентах. Начиная с 20 февраля 2020 г. авторы проводят работу по выращиванию саженцев сосны обыкновенной в лабораторных условиях по пяти экспериментальным методикам (февраль - май 2020 г.). Эксперимент № 1 проходит по методике гидропоники, эксперименты № 2 и № 4 - на двух твердых субстратах, эксперименты № 3 и 5 - на двух твердых субстратах и на четырех разных растворах по отдельности. Здесь вначале семена были посажены на почву, в состав которой вошли листовая почва, чернозем, песок в соотношении 1:2:1 соответственно. Когда саженцы достигли определенной длины, их пересадили на гидропонные сосуды из полиэтиленовых бутылей, где снизу подаются растворы. Твердым субстратом здесь явился песок, в который пересадили саженцы. На один раствор были высажены по 50 саженцев, итого на 4 раствора потребовалось 200 саженцев. Здесь надо подчеркнуть также, что авторами используется искусственное освещение (люминесцентные лампы). В июне 2020 г. планируется посадка саженцев на территории гари 10-летней давности в окрестностях с. Хаптагай. Посадка саженцев будет проведена на 4 участках. Каждый участок имеет размер 2х5м (участки № 1, 2, 3, 4). На участках № 1, 2 наблюдения за саженцами планируется провести 4 раза за вегетационный период (июнь - сентябрь). Эти участки являются контрольными. На участках № 3, 4 в летнее время будет уход за саженцами (полив, прополка, рыхление). Авторы также планируют создать мини-питомник закрытого типа в виде пленочной теплицы, где посадят саженцы на площадке 2 х5 м. В сентябре - октябре 2020 г. будет проведен сравнительный анализ естественного лесовосстановления соснового леса, естественного лесовосстановления после пожаров разных лет и искусственного лесовосстановления.

\section{Выводы}

В результате исследования и сравнения лесовосстановительных процессов в сосновых лесах после низовых пожаров 1-, 3-, 10-, 30-летней давности, нами было выявлено:

1. Сосновые леса в течение одного и трех лет после низовых пожаров не были восстановлены в связи с недостаточной увлажненностью почвы.

2. Лесовосстановительные процессы после пожаров 10-летней давности идут медленно, возможно из-за термокарстовых процессов. Здесь подрост достигает высоты в среднем 1 м.

3. 70\% территории, охваченной пожаром 10 лет назад, не были восстановлены в связи с вторичным пожаром 3-летней давности.

4. После низового пожара 30-летней давности сосновый лес интенсивно восстанавливается, и подрост достигает высоты в среднем 8-9 м.

5. По сравнению с контрольными участками, на территориях после пожаров 10-летней давности лесовосстановление идет интенсивнее в 1,5 раза, что подтверждается количеством подроста высотой 11-50 см (в среднем 23 экземпляра на контрольных участках, 34 образца - после пожара 10-летней давности), и в 9 раз больше количества подроста высотой свыше 150 см (1 экземпляр на контрольных участках, 7 и 12 экземпляров после пожаров 10-, 30-летней давности соответственно).

6. За 1 год подрост сосны обыкновенной в возрасте до 10 лет растет медленнее (10 см), а рост подроста в возрасте до 30-40 лет идет более интенсивно (30 и 33 см соответственно).

7. Работы по выращиванию саженцев сосны обыкновенной проводятся по пяти экспериментальным методикам. Экспери- 
мент № 1 проходит по методике гидропоники, эксперименты № 2 и 4 - на двух твердых субстратах, эксперименты № 3 и 5 - на двух твердых субстратах и на четырех разных растворах по отдельности.

В результате изучения различных источников и проведенного нами исследования, авторы в качестве лесовосстановительной меры предлагают создание питомников закрытого типа в виде пленочных теплиц.

В перспективе основной задачей проекта будет разработка определенной технологии по выращиванию и посадке саженцев сосны обыкновенной, а также обеспечение саженцами сосны обыкновенной детских образовательных учреждений Мегино-Кангаласского района (май - июнь 2021-2022 гг.).

\section{Список литературы / References}

1. Лыткина (Габышева) Л.П., Протопопова В.В. Лесные пожары как экологический фактор формирования лесов Центральной Якутии // Наука и образование. 2006. № 2 (42). C. $50-56$.

Lytkina (Gabysheva) L.P., Protopopova V.V. Forest fires as an environmental factor in the formation of forests in Central Yakutia// Science and Education. 2006. № 2 (42). P. 50 56 (in Russian).

2. Исаев А.П. Естественная и антропогенная динамика лиственничных лесов криолитозоны (на примере Якутии): автореф. ... дис. докт. биол. наук. Якутск, 2011. 42 с.

Isaev A.P. Natural and anthropogenic dynamics of larch forests of the permafrost zone (on the example of Yakutia): abstract ... dis. doct. biol. sciences. Yakutsk, 2011. 42 p.

3. Анализ лесных пожаров в Якутии / С.С. Анисимов, Р.Н. Дедюкин, А.И. Борисов и др. Текст: непосредственный, электронный // Молодой ученый. 2017. № 48 (182) C. 8-11. [Электронный pecypc]. URL: https://moluch.ru/archive/182/46912/ (дата обращения: 18.04.2020).

Analysis of forest fires in Yakutia/ S.S. Anisimov, R.N. Dedyukin, A.I. Borisov etc. Text: direct, electronic//
Young scientist. 2017. № 48 (182). P. 8-11. [Electronic resource]. URL: https://moluch.ru/archive/182/46912/ (accessed date: 04/18/2020) (in Russian)

4. Протопопова В.В., Габышева Л.П. Лесопожарное районирование лесного фонда Республики Саха (Якутия) // Успехи современного естествознания. 2016. № 8. С. 120-125.

Protopopova V.V., Gabysheva L.P. Forest fire zoning of the forest fund of the Republic of Sakha (Yakutia) // Successes in modern science. 2016. №. 8. P. 120-125 (in Russian).

5. ГКУ РС (Я) «Мегино-Кангаласское лесничество». [Электронный ресурс]. URL: https://kontragent.skrin. ru/issuers/1081415000424/63 (дата обращения: 21.04.2020).

GKU RS (Y) «Megino-Kangalassky Forestry». [Electronic resource]. URL: https://kontragent.skrin.ru/issuers/1081415000424/63 (accessed date: 21.04.2020) (in Russian).

6. Цветков П.А., Буряк Л.В. Исследование природы пожаров в лесах Сибири // Сибирский лесной журнал. 2014. № 3. C. 25-42.

Tsvetkov P.A., Buryak L.V. Investigation of the nature of fires in the forests of Siberia// Siberian Forest Journal. 2014. № 3. P. 25-42 (in Russian).

7. Заболоцкий В.И., Баранник Л.П. Лесорастительные условия в горельниках юго-западной части ленточных боров Алтайского края // Лесное хозяйство. 2000. № 1. С. 52-54.

Zabolotsky V.I., Barannik L.P. Forest conditions in the burners of the southwestern part of the tape forests of the Altai Territory // Forestry. 2000. № 1. P. 52-54 (in Russian).

8. Габышева Л.П. Особенности послепожарного восстановления лиственницы в межаласных лесах Центральной Якутии // Научные ведомости Белгородского гос. ун-та. Серия Естественные науки. 2014. № 3 (174). Выпуск 26. С. 48-52.

Gabysheva L.P. Features of the post-fire restoration of larch in the interalass forests of Central Yakutia // Scientific reports of Belgorod State University. Series Natural Sciences. 2014. № 3 (174). Issue 26. P. 48-52 (in Russian).

9. Гордей Н.В., Тегленков Е.А. Исследование постпирогенных лесовозобновительных процессов в сосновых насаждениях // Труды БГТУ. № 1. Лесное хозяйство. Минск: Издательство БГТУ, 2015. № 1 С. 54-57.

Gordey N.V., Teglenkov E.A. The study of post-pyrogenic reforestation processes in pine stands// Works of Belorussian State Technological University. № 1. Forestry. Minsk: Publishing House of Belorussian State Technological University, 2015. № 1 (174). P. 54-57 (in Russian). 